\title{
Environmental noise exposure assessment from fireworks at festivals and pilgrimages in Northern Portugal
}

\author{
Robson Silva Passos ${ }^{\mathrm{a}, *}$, Cecília Alexandra Abreu Coelho da Rocha ${ }^{\mathrm{b}}$, António Pedro Oliveira de Carvalho ${ }^{\mathrm{c}}$, \\ Luiz Bueno da Silva ${ }^{\mathrm{d}}$, Ricardo Luís Alves da Silva ${ }^{\mathrm{e}}$ \\ a Academic Department of Environment, Health and Safety - Federal Institute of Education Science and Technology of Pernambuco, Brazil \\ ${ }^{\mathrm{b}}$ Citta - Research Centre for Territory, Transports and Environment, FEUP - Faculty of Engineering, U. Porto, 4200-465 Porto, Portugal \\ ${ }^{c}$ Lab. of Acoustics, FEUP - Faculty of Engineering, U. Porto, 4200-465 Porto, Portugal \\ ${ }^{\mathrm{d}}$ Production Engineering Department, Labor Analysis Laboratory, Federal University of Paraíba, Brazil \\ ${ }^{\mathrm{e}}$ Academic Department of Environment, Health and Safety - Federal Institute of Education Science and Technology of Pernambuco, Brazil
}

\section{A R T I C L E I N F O}

\section{Article history:}

Received 5 January 2021

Received in revised form 6 April 2021

Accepted 22 April 2021

Available online 19 May 2021

\section{Keywords:}

Noise exposure

Fireworks

Festivals

Pilgrimages

Hearing impairment

\begin{abstract}
A B S T R A C T
Although most research related to urban noise exposure, refers mainly to transportation noise, epidemiological research has already demonstrated the risks of leisure noise exposure, including fireworks, on children, the youth, and young adults thus denoting the need for further investigation. Cumulatively, the general population living near an event's location can also feel disturbed by this type of noise. This study investigated the noise produced by fireworks at events not yet evaluated, indicating the need for better noise management by the organizers, as well as a revision of the recent European Directive in addressing exposure limits for children. The objective of this study was to evaluate the noise exposure of the population of Northern Portugal during fireworks at festivals and pilgrimages. With that purpose, measurements and questionnaires were conducted at 27 non-pyromusical and pyromusical events. Events considered to be the largest or the most traditional events which occur annually in the Northern Region of Portugal. The measurement equipment was a type 1 sound level meter, from $01 \mathrm{~dB}$, positioned at the most exposed point, meaning, the area where the population was closest to the fireworks. The measurement time lasted for the entire duration of the firework explosions. The $\mathrm{L}_{\mathrm{Aeq}}, \mathrm{L}_{\mathrm{Amin}}, \mathrm{L}_{\mathrm{Amax}}$ values, as well as the statistical indicators, $\mathrm{L}_{\mathrm{A} 90}, \mathrm{~L}_{\mathrm{A} 50}$, and $\mathrm{L}_{\mathrm{A} 10}$, were determined with an impulsive response. The results showed that in $72 \%$ of the evaluated events, the exposure level exceeded $120 \mathrm{~dB}$ (A, imp), the limit- value defined by the Directive 2013/29 UE. The average $\mathrm{L}_{\mathrm{Amax}}, \mathrm{CI}$ $95 \%$ value, for the exposed population when assisting those events, ranged between 121 and 125 $120 \mathrm{~dB}$ (A, imp). Hypothesis tests performed for this sample, at a significance level of $5 \%$, demonstrated that there is no significant difference between the average exposure for both types of events, nonpyromusical and pyromusical. Considering that these noise levels can induce hearing impairment this study demonstrated the need for noise control measures for the people attending these types of events. Suggested solutions highlight the following safety measures: the use of quiet fireworks, the reduction of music volume at pyromusical events, changes to the public's position and an implementation of public sessions in order to raise the population's awareness about harmful noise effects, particularly for groups that are more sensitive to noise.
\end{abstract}

(c) 2021 Elsevier Ltd. All rights reserved.

\section{Introduction}

In the past three decades, several cities in Europe have been affected by recreational noise, mainly in city centers. Noise of recreational origin has been sparingly investigated and has not even been mentioned in the EEA Report, Noise in Europe 2014. In

\footnotetext{
* Corresponding author.

E-mail address: robsonpassos@recife.ifpe.edu.br (R. Silva Passos).
}

this report environmental noise is defined as "unwanted or harmful outdoor sound created by human activities, including noise emitted by means of transport, road traffic, rail traffic, air traffic and from sites of industrial activity" [1-3].

Festivals, pilgrimages, and fireworks are part of the Portuguese culture just as they are in a number of other countries. Currently, in Portugal there are $>14,000$ catalogued events [4]. It was possible to recognize, even with all the restrictions demanded by the present COVID-19 virus, that such events are a major instrument in 
enhancing economic development; a significant source of revenue, and a touristic attraction locally, regionally, and even at national level.

According to the size and duration of the event, which can range from a weekend to a month of festivities, visitor numbers can reach one million and it is common to see the presence of tourists from other Portuguese cities and from other countries. Some of these events have existed since the end of the fourteenth century. Most of them, about 5500 of the 14,000 events, occur in the northern part of the country [4].

One of the highlights of these events is the fireworks, with their colors and sounds which provide joy and fun for the population. The visitors appreciate the enchantment produced by the fireworks. In general, when mixed with music, the fireworks provide an air of rare beauty and harmony, where the sacred and the profane mix. These fireworks, used for the entertainment of people, produce noise that, depending on its intensity, and even without being noticed, can cause severe hearing damage to those who are there. All for the sole purpose of amusement. Many times, they are also referred to as a source of annoyance to the surrounding community and for domestic animals, thus being a threat to the overall sustainability of the event. On the other hand, at most events, the exposure to firework noise, follows exposure to highintensity noise from musical shows or exposure to noise from sound systems in amusement areas. The presence of many young people, exposed to intense noise, potentially increases the burden of noise exposure.

Fireworks commonly used during celebrations, express the festive mood with their sound, brightness, and sudden bursts of colours. However, since the early 1990s, epidemiological studies have indicated that leisure noise poses substantial danger, especially for children, adolescents, and young adults. It can eventually result in irreversible hearing loss, mainly due to long exposure to very noisy toys, fireworks or electronically amplified music such as in discotheques or at concerts $[5,6]$.

Noise from fireworks is considered impulsive noise and the effects on human hearing are particularly more aggressive than other types of noise, since a single exposure can, instantaneously, damage hearing $[7,8]$.

Auditory effects of noise, in particular, Noise-Induced Hearing Loss (NIHL) and tinnitus, can be induced by a single exposure to an intense impulse sound (such as a sudden loud blast sound) or by a chronic exposure with sound pressure levels (SPL) equal to or higher than 75-85 $\mathrm{dB}(\mathrm{A})$ (e.g., daily exposure with heavy construction equipment noise) [9].

Fireworks can produce noise peaks of about $160 \mathrm{~dB}(\mathrm{~A})$, which have the potential to cause a rupture of the tympanic membrane [10]. Some authors refer to values between 145 and $160 \mathrm{~dB}(\mathrm{~A})$, at $2 \mathrm{~m}$ distance or less [11]., and others, to sound levels of $190 \mathrm{~dB}$ (A) [12]. The tympanic membrane is an essential component of the tympanum-ossicular system for sound transmission. If a noise from an explosion punctures the eardrum, the victim may hear a buzzing sound for days, feel fullness, dizziness, suffer from headaches, as well as sensorineural (temporary or permanent) hearing loss. If a perforation of the tympanum becomes infected then hearing loss may worsen $[13,14]$.

In order to investigate the occurrence of acoustic trauma due to exposure to fireworks noise during New Year festivities, research was carried out in 562 centers in Germany, including the otorhinolaryngology departments of 31 university hospitals and 87 city hospitals. As well as a random sample of specialized private otorhinolaryngology clinics $(n=444)$. This study showed the existence of an extremely high number of cases of inner and middle ear damage resulting from New Year's fireworks, and these affect all ages, groups, and both sexes. There was a preponderance of children, adolescents, and male adults, especially young adults. Approxi- mately 8000 people were acoustically traumatized by New Year's Eve fireworks in that country [15].

The Department of Otorhinolaryngology at the University of Tel Aviv has analyzed acoustic trauma in 53 children, between the ages of 4 and 14 that were exposed to impulsive noise produced by toy guns and fireworks. The results showed that thirty-nine children were affected unilaterally, while fourteen presented bilateral hearing loss (from 67 ears tested). Most hearing loss (>70\%) was high frequency sensorineural, while nine of the 67 injured ears had sensorineural hearing loss at medium frequencies. Seven children underwent a traumatic perforation of the tympanic membrane. Dizziness or tinnitus was reported by twenty children. After six months of follow-up, $15 \%$ of the children had returned to normal hearing, while $85 \%$ still had mild hearing loss [16].

In Poland, a study in the city of Kraków was carried out during the 2016 and 2017 New Year festivities. The study assessed noise from fireworks. This study found high levels of firework noise and suggested the adoption of noise control actions both for the professionals involved, and for the people present at the events [17].

According to Maassen $\mathrm{M}$ et al. [5], this type of leisure noise can cause damage to the ear due to the following reasons:

- Exposure to impulsive noise presents a higher level of risk to human health than exposure to continuous noise.

- The subjective intensity of impulsive noise, due to its short duration, does not correspond to the peak level.

- In leisure activities, almost no attention is given to the possible harmful effects produced by such exposure, since these noises are associated with a positive experience such as joy and the beauty produced by the explosion of fireworks.

In 1999 WHO revised the suggested exposure limits to the noise produced by fireworks. These limits intend to avoid such critical health effects, like hearing impairment, for adults and children, respectively, at peak noise values of $140 \mathrm{~dB}(\mathrm{C})$ and $120 \mathrm{~dB}(\mathrm{C})$, evaluated at $0,1 \mathrm{~m}$ from the ear [18]. In 2004, the UK adopted a noise pollution policy that resulted in the prohibition of fireworks from $11 \mathrm{pm}$ to 7am. The exceptions are the Chinese New Year party, Diwali, New Year, and Bonfire Night. However, for all types of events, the use of fireworks that produce a sound level above $120 \mathrm{~dB}$ (A, imp), at $15 \mathrm{~m}$ from the source, are not permitted [19]

In India, with the aim to protect the elderly and sick, studies were conducted to reduce the noise produced by fireworks to the legal standards of sound levels established since 2005, which is $125 \mathrm{~dB}(\mathrm{~A})$, at $4 \mathrm{~m}$ away. Efforts have been made to revise the chemical composition of explosives and obtain a result that complies with the legislation and does not diminish the beauty of the fireworks [20]. A Pollution Control Council seeks to guarantee the Constitutional Right to live in an environment free from noise pollution, and there is a ban on fireworks from 10:00 pm to 6:00 am [21].

In Portugal in 2007, the Public Security Police [22], following Directive 2007/23/EU of the European Parliament and of the Council [23]., issued instructions on the use of pyrotechnic articles, like fireworks, classifying them as type F1, F2, and F3. That label required minimum safety distances of $1 \mathrm{~m}, 8 \mathrm{~m}$, or $15 \mathrm{~m}$ for their use. Additionally, the maximum sound level produced by fireworks must not exceed $120 \mathrm{~dB}$ (A, imp), or an equivalent sound level measured by another suitable method at a safe distance.

In 2013, the European Union, in view of the problems related to the use of fireworks, published the Directive 2013/29 / EU of the European Parliament and of the Council, which adopted the same classification and exposure criteria as those required in Portugal [24]. 
Apart from auditory effects, non-auditory effects are also relevant in the context of environmental noise. Human and animals both suffer from excessive noise, including stress, which can generate a series of adverse health effects for both [9,25-27]- The stress during either period caused HPA-axis hyperactivity, lower performance in all cognitive and motor tasks, a reduction of size in the hippocampal formation, $\mathrm{MPFC}$, and amygdala, and a reduced neuronal density in the MPFC and dentate gyrus (DG) [28]. Recent studies indicate an increased risk of diabetes mellitus associated with excessive noise exposure [29].

The response that shows the highest prevalence in relation to the existence of environmental noise is annoyance. Annoyance contributes substantially to the burden of disease produced by this agent. This effect, which is characterized by irritation, can result from noise by interfering with daily activities, feelings, thoughts, sleep or rest, and can be accompanied by negative responses, such as: anger, disgust, fatigue, and stress-related symptoms [30,31].

Annoyance caused by excessive noise is induced by three factors: noise level, context, and the individual. In fact, reducing sound pressure level does not necessarily reduce noise annoyance since the context and personal characteristics are variables that are not controlled by the technical measures adopted for noise control. Regarding the context, many factors such as the time of day, the location, the nature of the source, an internal or external environment, at work or at home, and any type of activity (working, leisure, studying, relaxing or sleeping), can all directly interfere with noise annoyance. Individual factors include age, proximity to the source, individual sensitivity, and attitudes towards the source. All of these directly influence noise annoyance [32].

Noise annoyance caused by noisy events in the surrounding community is a relevant aspect that must be considered for the establishment of public policies when it comes to noise exposure from fireworks.

Environmental factors have recently been considered as possible risk factors for the population in relation to Alzheimer's disease (AD) [33]. Noise appears to be a risk factor for cardiovascular disease, associated with an increased risk of vascular dementia and Alzheimer's disease [34]. It seems likely that noise may play a role in the mechanistic path of Alzheimer's disease pathology [35]. According to OECD [36]., Portugal ranks fourth in the world ranking for dementia, behind only Japan, Italy, and Germany. It is estimated that about $5,91 \%$ of the population of Portugal, above 60 years old, suffer from this disease [37]. Dementia is the clinical expression of several pathological entities. Alzheimer's disease (AD) is the most prevalent, accounting for 50 to $70 \%$ of cases [37]. Since the number of people with this disease is high, identifying and understanding the risk factors for AD development is relevant [35]. It is not difficult to see why people who suffer from dementia are easily stressed by firework noise. They simply no longer recognize this type of noise as they did before the disease developed.

The annoyance produced by the noise becomes even more aggravating for people suffering from Post-Traumatic Stress Disorder (PTSD). This disorder can develop when a person has been exposed to one or more tragic events, such as: violence, disasters, severe accidents, or military actions [38]. Portugal has veterans of Colonial wars and the Afghanistan conflict for military personnel who suffer from post-traumatic stress disorder due to having participated in wars, the explosion of fireworks can generate memories of explosions, bombs, and weapons. Some become alarmed to the point of panic, irritability, or even outbursts of anger. Among the symptoms reported by Portuguese ex-combatants of the socalled Colonial War, about $48 \%$ answered that they became more nervous, or more easily fearful of noises or movements. More recently, a study from the University of Minho revealed that about
$11 \%$ of the military personnel who were in the Afghanistan War had PTSD symptoms $[39,40]$.

\section{Materials and methods}

\subsection{Characterization of the research area}

Festivals and popular pilgrimages in Portugal take place throughout the country and 14,282 of them are registered. Most events occur in summer with about 6900 events, followed by spring, with just over 4100 , and the rest during autumn and winter. In relation to months, the highest numbers occur in the month of August, with a total of 3600 events, followed by the month of June, with 2000, and then the months of July and September, with 1500 events each and, finally, the month of May, with 1000. Data collection took place in the Northern region of Portugal, because it holds the largest number of events in the country. About $38 \%$ of the events take place in the region of interest of this research. The North region of Portugal consists of 5 districts: Braga, Bragança, Porto, Viana do Castelo, Vila Real, and parts of the districts of Aveiro and Viseu.

\subsection{Evaluation of the sound pressure level}

The research was carried out on 27 non-pyromusical and pyromusical events in all districts of Northern Portugal. For the noise evaluation, the sound level meter $01 \mathrm{~dB}$ type, was used with a measuring range of 40 to $140 \mathrm{~dB}$. It was positioned at the point where the public were as closes as possible to the fireworks as permitted by either the police authority or event organizers. The distance between the public and the places where the fireworks are positioned (Fig. 1), varies according to each situation. Fireworks can be installed on firm ground or on boats on the riverbed.

Fig. 2 shows a map of the northern region of Portugal where the municipalities are indicated, indicated by arrows, in which the noise assessments occurred.

The selection of these locations was based on the following parameters:

- Evaluation of the noise produced by fireworks in the most important festivals; at the most popular pilgrimages in the North of Portugal; in each capital of each district of the region: occurring from May to September.

- When it was not possible to evaluate the most important events, due to coincidence of dates, the second most important one was chosen, so that all the districts in the north of Portugal had at least one event evaluated. This was the case, for example, in the District of Braga, where a traditional event was evaluated in the first capital of Portugal, the city of Guimarães.

- The cost-benefit of the evaluation of the event, which led to a greater number of event evaluations in the so-called Greater Porto region.

- Climatic conditions that occasionally prevented the assessment.

Table 1 shows the districts, municipalities, measurement time, type of show, and estimated distance of evaluation between the population and firework blast points. The sample consists of 27 observations, 19 with fireworks (non-pyromusical) events, and 8 pyromusical events.

\subsection{Hypothesis tests}

To objectively verify if the $\mathrm{L}_{\text {Aeq }}$ and $\mathrm{L}_{\text {Amax }}$ values exceeded the exposure value adopted by Portugal and the European Union the $t$-test for a sample was applied. It was also verified for sample to 

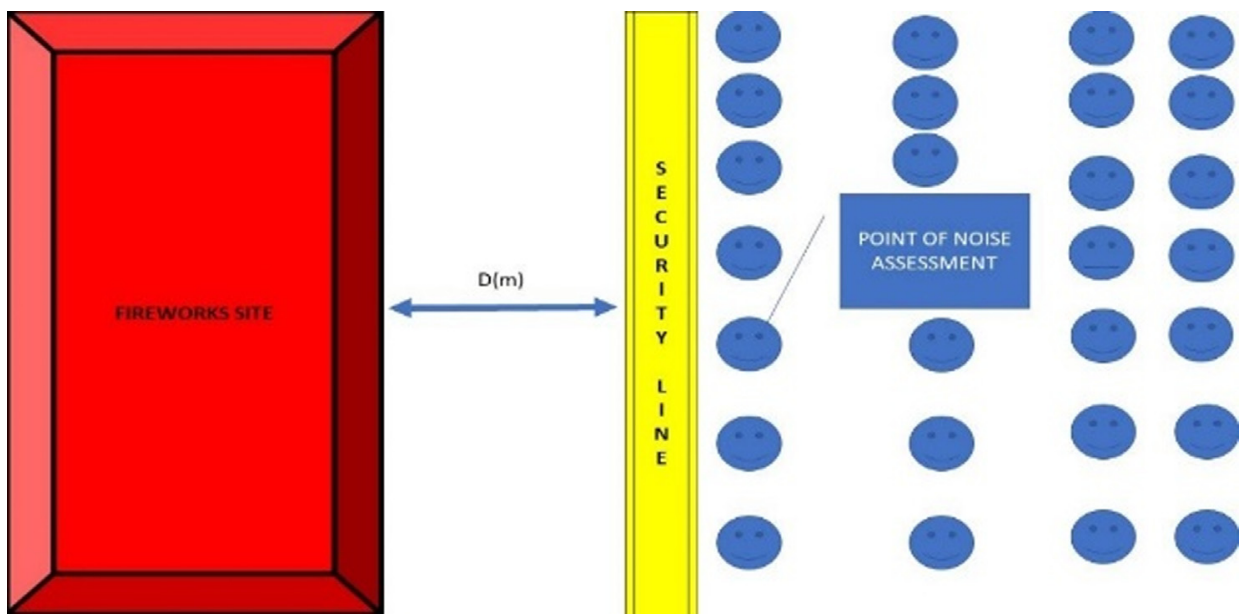

Fig. 1. Fireworks noise assessment scheme.

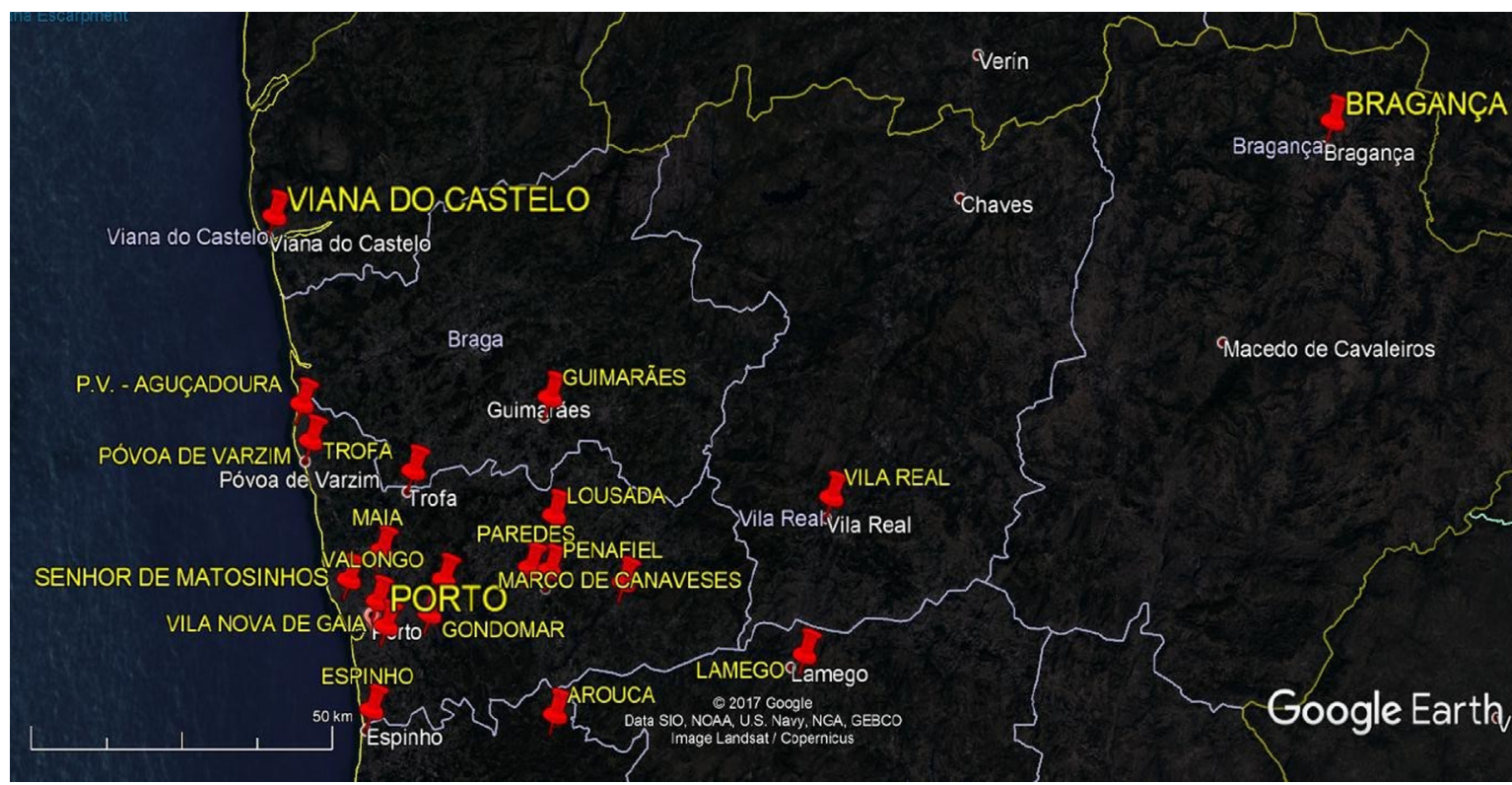

Fig. 2. Map of the northern region of Portugal showing the municipalities that had events evaluated.

see if there was a difference between the intensity of exposure for pyromusical and non-pyromusical shows. In this case, Student's $t$ test for independent samples was applied.

\section{Results}

\subsection{Evaluation of the sound pressure level}

Table 2 shows the results of $\mathrm{L}_{\mathrm{Aeq}}, \mathrm{L}_{\mathrm{Amin}}, \mathrm{L}_{\mathrm{Amax}}$, the statistical indices $\mathrm{L}_{\mathrm{A} 90}, \mathrm{~L}_{\mathrm{A} 50}$, and $\mathrm{L}_{\mathrm{A} 10}$ for impulsive noise and peak level. The $\mathrm{L}_{\mathrm{Amax}}$ indicator is associated with discomfort related to the harmful effects produced by an events sound. It is used to evaluate maximum sound levels during the period of evaluation.

The statistical indices Ln represent the sound pressure level exceeded for $n$ percent of the measurement time. In other words, for $\mathrm{n}$ percent of the time, fluctuations in sound pressure levels were greater than the Ln level. The $\mathrm{L}_{\mathrm{A} 10}$ is the level exceeded by $10 \%$ of the measurement time. For $10 \%$ of the time, sound or noise has a sound pressure level above the value of $\mathrm{L}_{\mathrm{A} 10}$. For the rest of the time, sound or noise has a sound pressure level equal to or less than $\mathrm{L}_{\mathrm{A} 10}$. This indicator represents, with good probability, the level of sound pressure referring to sporadic or intermittent events. The $\mathrm{L}_{\mathrm{A} 50}$ is the level exceeded by $50 \%$ of the measurement time. It indicates, statistically, the midpoint of the noise readings. This represents an average of the fluctuating noise levels. The $L_{A 90}$ is the level exceeded by $90 \%$ of the measurement time. For $90 \%$ of the time, noise levels were above this level. For practical purposes, and when adopting statistical techniques, the $\mathrm{L}_{\mathrm{A} 90}$ is considered as background or residual noise level.

The peak level was used here to compare the noise exposure patterns of fireworks with values established by the World Health Organization.

Table 3 shows the mean values, standard deviation, coefficient of variation, minimum and maximum values of $\mathrm{L}_{\mathrm{Aeq}}, \mathrm{L}_{\mathrm{Amin}}, \mathrm{L}_{\mathrm{Amax}}$, $\mathrm{L}_{\mathrm{A} 90}, \mathrm{~L}_{\mathrm{A} 50}, \mathrm{~L}_{\mathrm{A} 10}$ for impulsive noise, the error, and the lower and upper confidence interval for a confidence level (CI) of $95 \%$.

\subsection{Hypothesis tests}

For $\mathrm{L}_{\mathrm{Aeq}}$ and $\mathrm{L}_{\mathrm{Amax}}$ values were found to have a normal distribution since the value p ( $>0.200$ for both) is $>5 \%$. In this way, it was possible to apply the Student $t$-test for a sample. Table 4 below 
Table 1

Districts, municipalities, measurement time, type of show, and estimated distance of evaluation.

\begin{tabular}{|c|c|c|c|c|}
\hline District & City & $\mathrm{T}(\min )$ & Type & $\mathrm{D}(\mathrm{m})$ \\
\hline \multirow[t]{2}{*}{ Aveiro } & Arouca & 11 & pyromusical & 20 \\
\hline & Espinho & 20 & pyromusical & 150 \\
\hline Braga & Guimarães & 20 & pyromusical & 150 \\
\hline Bragança & Bragança & 14 & non-pyromusical & 150 \\
\hline \multirow[t]{19}{*}{ Porto } & Gondomar & 20 & non-pyromusical & 150 \\
\hline & Lousada & 8 & non-pyromusical & 150 \\
\hline & Lousada & 22 & non-pyromusical & 150 \\
\hline & Lousada & 14 & non-pyromusical & 150 \\
\hline & Maia & 12 & non-pyromusical & 150 \\
\hline & Maia & 14 & pyromusical & 120 \\
\hline & Marco de Canaveses & 20 & Pyromusical & 150 \\
\hline & Matosinhos & 24 & non-pyromusical & 150 \\
\hline & Matosinhos (children's show) & 29 & non-pyromusical & 20 \\
\hline & Paredes & 11 & non-pyromusical & 200 \\
\hline & Penafiel & 13 & non-pyromusical & 150 \\
\hline & Porto & 16 & Pyromusical & 150 \\
\hline & Póvoa de Varzim & 13 & non-pyromusical & 100 \\
\hline & Póvoa de Varzim & 05 & non-pyromusical & 100 \\
\hline & Póvoa de Varzim & 06 & non-pyromusical & 100 \\
\hline & Trofa & 16 & non-pyromusical & 50 \\
\hline & Valongo & 13 & non-pyromusical & 150 \\
\hline & Valongo & 11 & non-pyromusical & 150 \\
\hline & Vila Nova de Gaia & 16 & Pyromusical & 150 \\
\hline \multirow[t]{2}{*}{ V.Castelo } & Viana do Castelo & 12 & non-pyromusical & 150 \\
\hline & Viana do Castelo & 23 & pyromusical & 50 \\
\hline Vila Real & Vila Real & 46 & non-pyromusical & 150 \\
\hline Viseu & Lamego & 15 & non-pyromusical & 150 \\
\hline
\end{tabular}

Table 2

Results of $\mathrm{L}_{\mathrm{Aeq}}, \mathrm{L}_{\mathrm{Amin}}, \mathrm{L}_{\mathrm{Amax}}, \mathrm{L}_{\mathrm{A} 90}, \mathrm{~L}_{\mathrm{A} 50}$, and $\mathrm{L}_{\mathrm{A} 10}$ for impulsive noise and peak level.

\begin{tabular}{|c|c|c|c|c|c|c|c|c|}
\hline City & Type & $\mathrm{L}_{\text {Aeq }}$ & $\mathrm{L}_{\mathrm{Amin}}$ & $\mathrm{L}_{\text {Amax }}$ & $\mathrm{L}_{\mathrm{A} 90}$ & $\mathrm{~L}_{\mathrm{A} 50}$ & $\mathrm{~L}_{\mathrm{A} 10}$ & Peak dB(C) \\
\hline Arouca & Pyromusical & 109.2 & 74.3 & 123 & 100.1 & 105.4 & 110.7 & $>140$ \\
\hline Espinho & Pyromusical & 103.9 & 64.9 & 116.4 & 84.1 & 100.2 & 108.2 & 137.4 \\
\hline Guimarães & Pyromusical & 106.4 & 73.5 & 127.1 & 90.9 & 102.6 & 108.1 & $>140$ \\
\hline Bragança & non-pyromusical & 106 & 63.3 & 120.1 & 90.7 & 104.3 & 108.8 & 139.3 \\
\hline Gondomar & non-pyromusical & 106.8 & 63.7 & 124 & 73.8 & 98.5 & 110.6 & $>140$ \\
\hline Lousada & non-pyromusical & 112.9 & 67 & 122.4 & 107.3 & 111.6 & 115.6 & $>140$ \\
\hline Lousada & non-pyromusical & 113.4 & 77.8 & 126.9 & 97.8 & 112 & 116.6 & $>140$ \\
\hline Lousada & non-pyromusical & 113.3 & 67.1 & 122.9 & 100.3 & 112.1 & 116.5 & $>140$ \\
\hline Maia & non-pyromusical & 98.3 & 59.9 & 111.2 & 69.8 & 86.8 & 101.2 & 135 \\
\hline Maia & Pyromusical & 107.6 & 86.8 & 125.7 & 96.6 & 104.6 & 109.5 & $>140$ \\
\hline Marco de Canaveses & Pyromusical & 103,5 & 78,9 & 123,3 & 90,8 & 99,6 & 105,2 & $>140$ \\
\hline Matosinhos & non-pyromusical & 110.5 & 72.5 & 129.9 & 91.8 & 106.3 & 112.6 & $>140$ \\
\hline Matosinhos & non-pyromusical (children's show) & 109.5 & 72 & 128 & 83.2 & 91.5 & 105.8 & $>140$ \\
\hline Paredes & non-pyromusical & 108,5 & 72,9 & 123 & 99,9 & 106,8 & 110,9 & $>140$ \\
\hline Penafiel & non-pyromusical & 110.1 & 95.6 & 118.1 & 104.5 & 108.6 & 113.1 & $>140$ \\
\hline Porto & Pyromusical & 104,5 & 88,7 & 120,2 & 98,4 & 103 & 106,6 & 140 \\
\hline Póvoa de Varzim & non-pyromusical & 112.3 & 57.1 & 127.4 & 91.1 & 110.9 & 114.8 & $>140$ \\
\hline Póvoa de Varzim & non-pyromusical & 110.3 & 95 & 121.2 & 101 & 109 & 112.6 & $>140$ \\
\hline Póvoa de Varzim & non-pyromusical & 110,6 & 93,5 & 124,4 & 105,7 & 109,2 & 112,5 & $>140$ \\
\hline Trofa & non-pyromusical & 111.6 & 60 & 127.3 & 66.1 & 106.1 & 114.4 & $>140$ \\
\hline Valongo & non-pyromusical & 108.6 & 63.2 & 126.2 & 86.1 & 100 & 111.2 & $>140$ \\
\hline Valongo & non-pyromusical & 105.3 & 69.4 & 122.5 & 80.7 & 95.9 & 107.5 & $>140$ \\
\hline Viana do Castelo & non-pyromusical & 106.1 & 63.5 & 119.6 & 71.2 & 96.4 & 110.4 & $>140$ \\
\hline Viana do Castelo & Pyromusical & 99.6 & 61.1 & 113.1 & 80.2 & 93.9 & 103.8 & 136 \\
\hline Vila Nova de Gaia & Pyromusical & 102 & 72,4 & 120,4 & 82,8 & 95,4 & 105,8 & 139.7 \\
\hline Vila Real & non-pyromusical & 110.4 & 65.1 & 123.7 & 102.8 & 108.5 & 113.3 & $>140$ \\
\hline Lamego & non-pyromusical & 111.7 & 63.2 & 128.1 & 90.7 & 106.7 & 113 & $>140$ \\
\hline
\end{tabular}

Table 3

Statistic of the evaluated parameters.

\begin{tabular}{|c|c|c|c|c|c|c|c|c|c|}
\hline & & & & & & & & $\mathrm{Cl} 95 \%$ & \\
\hline & $\mathrm{N}$ & Average & Standart deviation & Coefficient of variation & Minimum & Maximum & Error & Lower & Upper \\
\hline $\mathrm{L}_{\text {Aeq }}$ & 27 & 107.88 & 4,05 & $3.75 \%$ & 98.3 & 113,4 & 0.8 & 106.28 & 109.49 \\
\hline LAmin & 27 & 71.94 & 11.25 & $15.61 \%$ & 57.1 & 95.6 & 2.16 & 67.49 & 76.39 \\
\hline $\mathrm{L}_{\text {Amax }}$ & 27 & 122,82 & 4,52 & $3.7 \%$ & 111 & 130 & 0.87 & 121.30 & 124.6 \\
\hline $\mathrm{L}_{\mathrm{A} 90}$ & 27 & 90.31 & 11.52 & $12.75 \%$ & 66.1 & 107.3 & 2.22 & 85.7 & 94.9 \\
\hline $\mathrm{L}_{\mathrm{A} 50}$ & 27 & 103.18 & 6.71 & $6.5 \%$ & 86.8 & 112.1 & 1.29 & 100.5 & 105.8 \\
\hline $\mathrm{L}_{\mathrm{A} 10}$ & 27 & 110.34 & 3,96 & $3.58 \%$ & 101.2 & 116.6 & 0.76 & 108.8 & 111.9 \\
\hline
\end{tabular}


shows the descriptive statistics and tests $t$ for a sample where a comparison was made between the average $\mathrm{L}_{\mathrm{Aeq}}$ and $\mathrm{L}_{\mathrm{Amax}}$ values and the reference value of $120 \mathrm{~dB}(\mathrm{~A}, \mathrm{imp})$.

Fig. 3 shows a graph comparing the average values of $L_{\text {Aeq }}$ and $\mathrm{L}_{\mathrm{Amax}}$ with the reference value of $120 \mathrm{~dB}$ (A, imp).

The assumption of normality was found for both nonpyromusical and pyromusical qualitative variables since all the test values are higher than $5 \%$ (table 5). Therefore, the null hypothesis is not rejected, and the Student's t-parametric test can be used, for two independent samples.

Table 6 shows the result of the Student's $t$-test where it can be seen that the $\mathrm{p}$-value for $\mathrm{L}_{\text {Aeq }}$ variable is less than $5 \%$ while the LAmax variable is greater than $5 \%$.

Fig. 4 shows the relationship between the average values of $\mathrm{L}_{\text {Aeq }}$ and $\mathrm{L}_{\mathrm{Amax}}$ and the events (pyromusical and non-pyromusical).

Last but not least, attention should be paid to the exposure limits laid down in the 2013 European Directive, which sets the limit at $120 \mathrm{~dB}(\mathrm{~A}, \mathrm{imp}$.) For the whole population, if we compare this value with that established by WHO of $120 \mathrm{~dB}$ (C) for children, we will verify that in an analysis of the accumulated distribution of noise intensity (when we use the European standard) we will observe for all the investigated cases, that values above $120 \mathrm{~dB}$ (A, imp.) are rare and sometimes practically non-existent. However, if we adopt the WHO standard of $120 \mathrm{~dB}(\mathrm{C})$, we will verify that above this value, for all cases analyzed, we will still have high levels of exposure, which is a serious public health problem. Especially, considering that this part of the population (children and infants) is always present in these events without any kind of protection.

Fig. 5 shows the result of the cumulative distribution of noise produced by thé fireworks of the feast in the municipality of Vila Real (Mouçós). On the left side of the figure, we see the exposure considering the impulse weighting, as recommended by the European directive (120 $\mathrm{dB}(\mathrm{A})$, imp.). On the right side is the exposure taking into consideration the limit for WHO regarding children $(120 \mathrm{~dB}(\mathrm{C}))$. It is noted that if we adopt the European Union standard, we will have the impression of non- exposure above the threshold, whereas if we use the WHO standard, we will be sure that there is exposure above the threshold. That is if we adopt the limit of $120 \mathrm{~dB}$ (A, imp.) we can reach the conclusion that there is no exposure to noise above this limit for any individual of the public yet when adopting the value of $120 \mathrm{~dB}(\mathrm{C})$, we will see that at least one group considered vulnerable by the WHO, is exposed to high levels. This may generate the feeling of a falseness of safety in relation to the environmental noise agent for the case of the fireworks display. Therefore, it is more advisable to adopt the WHO limit that avoids generating a false negative exposure. This result was repeated in all other evaluated events.

\section{Discussion}

In the sample, the $\mathrm{L}_{\text {Aeq }}$ has an average value of $107.8 \mathrm{~dB}(\mathrm{~A})$, with a dispersion of values of $4.05 \%$, the minimum and maximum values being, respectively, $98.3 \mathrm{~dB}(\mathrm{~A})$ and $113.4 \mathrm{~dB}(\mathrm{~A})$; The $\mathrm{L}_{\mathrm{Amax}}$ has an average value of $122.8 \mathrm{~dB}(\mathrm{~A})$, with a dispersion of values of $4.5 \%$, the minimum and maximum values being, respectively, $111 \mathrm{~dB}$ (A) and $130 \mathrm{~dB}(\mathrm{~A})$. It can be observed that for the sample, about

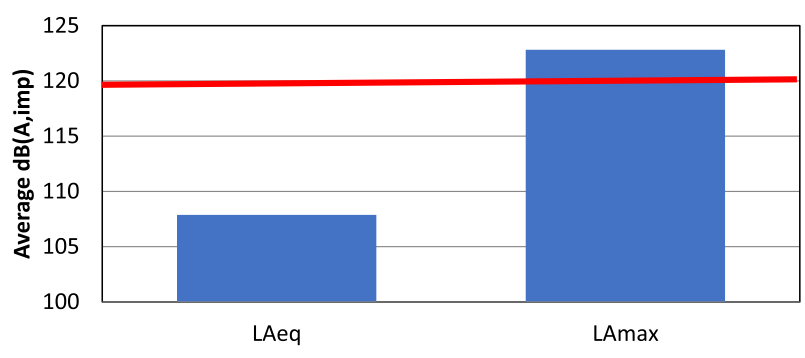

Fig. 3. Comparing the average values of LAeq and LAmax with the reference value of $120 \mathrm{~dB}(\mathrm{~A}, \mathrm{imp})$.

$78 \%$ of events exceed the limit of $120 \mathrm{~dB}$ (A, imp) determined by the Public Security Police of Portugal and proposed by the European Union for its Member States.

On the other hand, in about $78 \%$ of the evaluated events the population is exposed to peak values above $140 \mathrm{~dB}(\mathrm{C})$ and $100 \%$ of them are exposed to peak values above the $120 \mathrm{~dB}(\mathrm{C})$ exposure limits by WHO. The minimum value found was $135 \mathrm{~dB}(\mathrm{C})$. The minimum peak level values, except for the maximum intense value, exceeded the maximum values found in shooting exercises with a Heavy Machine Gun (HMG) on the military ship HMS Grimsby. The HMG, is a $12.7 \mathrm{~mm}$ caliber ( $0.50 \mathrm{in}$.) weapon type L111A1. These values were, according to the place evaluated, $160.7 \mathrm{~dB}(\mathrm{C})$ (bridge wing) (value not exceeded), $122.7 \mathrm{~dB}(\mathrm{C})$ (starboard door), $117.0 \mathrm{~dB}(\mathrm{C})$ (port door) e $112.0 \mathrm{~dB}(\mathrm{C})$ (centre) [40].

The results of this investigation also showed that the $\mathrm{L}_{\mathrm{Amax}}$ values, for the most part, were greater than those produced by teams that operate heavy war weapons, such as Tanks -T72, Anti-tanks type PPK MALUTKA and $73 \mathrm{~mm}$ gun on BWP-1. Impact noise values found were higher than those produced by the operation teams of the PPK MALUTKA anti-tank gun unit and comparable to those of the T-72 tank (Młynski R. et al.,2018). During a military exercise, 27 soldiers suffered an emergency due to acute trauma due to impact noise, resulting in hospitalization. All had hearing loss in the $4 \mathrm{~Hz}$ range. After a period of treatment, 11 still had tinnitus [8]. By comparing these results, we can say that the public that attend events with noise as or more intense than heavy weapons of war have a high risk of hearing damage. In this regard, babies, children, young people, and young adults, can damage their hearing for the rest of their lives, with consequences such as personal communication issues, social coexistence problems, and decreased levels of employability.

Extrapolating to the population of Northern Portugal, considering a margin of error of 0.87 , it is safe to state, with $95 \%$ confidence, that the true $\mathrm{L}_{\mathrm{Amax}}$ average is in the confidence interval [121.3;124.6]. For the $\mathrm{L}_{\text {Aeq }}$ value, considering the margin of error of 0.8 , it can be concluded, for the population, that the true average is in the confidence interval [106.2;109.4].

In the sample statistical indicators show that, $90 \%$ of the time, the people present are exposed to noise with an average value of $90.3 \mathrm{~dB}(\mathrm{~A}) .50 \%$ of the time, they are exposed tt $t$ to an average noise of $103.1 \mathrm{~dB}(\mathrm{~A})$, and that in $10 \%$ of the event time this average value is $110.3 \mathrm{~dB}(\mathrm{~A})$. Analyzing in a more detailed way, one can see, for example, that for one of the festivals in the city of Lousada, which presents the highest values for these indices, the attendees

Table 4

Descriptive statistics and tests $\mathrm{t}$ for a sample for LAeq and LAmax.

\begin{tabular}{|c|c|c|c|c|c|c|}
\hline & $\mathrm{N}$ & Average & Standard deviation & $t_{21}$ & $\mathrm{gl}$ & $\mathrm{p}$ \\
\hline LAeq & 27 & 107.88 & 4,05 & $-15,518$ & 26 & $* * 0,000$ \\
\hline LAmax & 27 & 122,82 & 4,52 & 3.238 & 26 & $* 0,03$ \\
\hline
\end{tabular}

* Significant difference for $\mathrm{p}<0.05^{* *}$ significant difference for $\mathrm{p}<0.01$ 
Table 5

K-S test: Verification of the normality of the distribution of LAeq and LAmax values in the two classes (non-pyromusical and pyromusical).

\begin{tabular}{|c|c|c|c|c|}
\hline \multicolumn{5}{|l|}{ K-S (a) } \\
\hline & & Statistic & $\mathrm{gl}$ & $\mathrm{P}$ \\
\hline \multirow[t]{2}{*}{$\mathrm{L}_{\text {Aeq }}$} & Non-pyromusical & ,187 & 18 & $>0,200$ \\
\hline & Pyromusical & ,136 & 7 & $>0,200$ \\
\hline \multirow[t]{2}{*}{$\mathrm{L}_{\text {Amax }}$} & Non-pyromusical & ,169 & 18 & $>0,200$ \\
\hline & Pyromusical & ,226 & 7 & $>0,200$ \\
\hline
\end{tabular}

a- Correction of Significance of Lilliefors

Table 6

Result of the Student's $t$ for $\mathrm{L}_{\mathrm{Aeq}}$ e $\mathrm{L}_{\mathrm{Amax}}$.

\begin{tabular}{|c|c|c|c|c|c|c|}
\hline & & $\mathrm{N}$ & Average & Standard deviation & $t_{20}$ & $\mathrm{P}$ \\
\hline \multirow[t]{2}{*}{$\mathrm{L}_{\text {Aeq }}$} & Non-pyromusical & 19 & 109,27 & 3,630 & 3,187 & 0,04 \\
\hline & Pyromusical & 8 & 104,59 & 3,090 & & \\
\hline \multirow[t]{2}{*}{$\mathrm{L}_{\mathrm{Amax}}$} & Non-pyromusical & 19 & 123,52 & 4,392 & 1.258 & 0,220 \\
\hline & Pyromusical & 8 & 121,15 & 4,674 & & \\
\hline
\end{tabular}

The hypothesis test for a sample showed that, in the area where

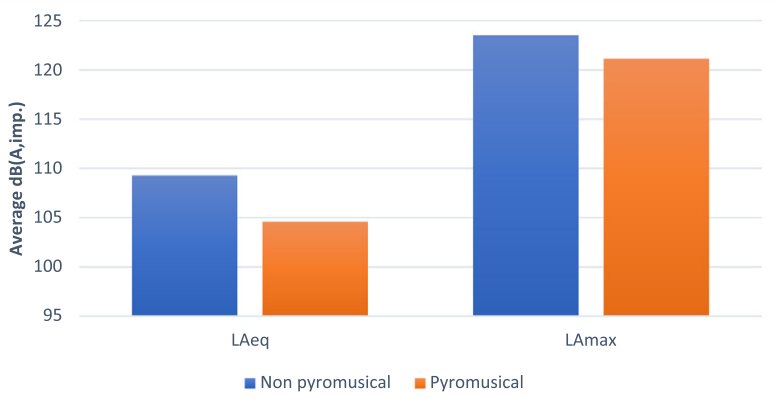

Fig. 4. Relations between the average values of LAeq and LAmax and the events (pyromusical and non-pyromusical).

were exposed to, for $11 \mathrm{~min}$, the $\mathrm{L}_{\mathrm{A} 50}$ of $112 \mathrm{~dB}(\mathrm{~A})$ and at Vila Real festival, the largest in terms of exposure time, the public were exposed for $23 \mathrm{~min}$ to the $\mathrm{L}_{\mathrm{A} 50}$ of $108 \mathrm{~dB}(\mathrm{~A})$. the population attends the show, the average $\mathrm{L}_{\text {Aeq }}$ value is significantly lower than $120 \mathrm{~dB}\left(\mathrm{~A}\right.$, imp) and the mean $\mathrm{L}_{\mathrm{Amax}}$ value is significantly higher than $120 \mathrm{~dB}(\mathrm{~A}$, imp). Differences are statistically significant. Thus, the mean value of $\mathrm{L}_{\text {Aeq }}$ is below 120 (A, imp) for the population and the mean value of $L_{\text {Amax }}$ exceeds the value of 120 (A, imp) for the population, which represents a risk of hearing impairment for those people who attend this type of event, in particular for hyposensitive groups such as young adults, children, infants, and the elderly.

The hypothesis test for two independent samples showed that in the sample the mean value of $\mathrm{L}_{\mathrm{Aeq}}$ and $\mathrm{L}_{\mathrm{Amax}}$ is higher for nonpyromusical events. The observed differences are statistically significant for $\mathrm{L}_{\mathrm{Aeq}}(\mathrm{p}=0.04)$. Thus, we can affirm that there is a difference of exposure in pyromusical and non-pyromusical fireworks, for $\mathrm{L}_{\text {Aeq }}$. That is, the mean value of the intensity of the noise produced by fireworks in non-pyromusical events is significantly higher than the average noise produced in the pyromusical events.

However, for $\mathrm{L}_{\mathrm{Amax}}(\mathrm{p}=0.220)$ we cannot affirm that there is a difference of exposure in pyromusical and non-pyromusical fireworks.

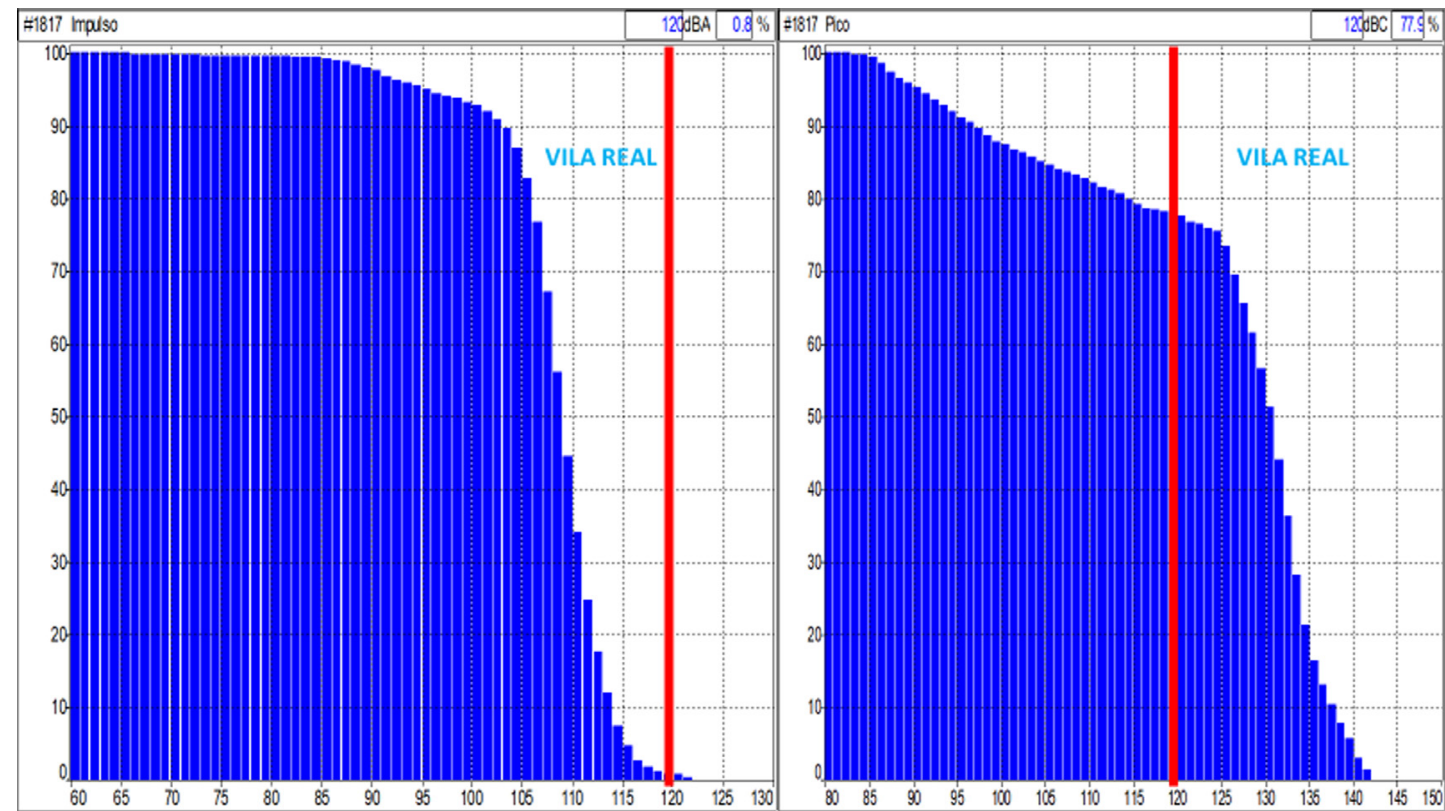

Fig. 5. Accumulated distribution of fireworks noise. 
The fact that the noise of the non-pyromusical show has higher intensity values than the pyromusical events could be explained by the variation of the measurement distance, wind speed variations, and the direction of the wind at the time of measurement. Or, it may be in the face of a destructive interference case, that is, the musical sound waves may be "canceling" the impulse produced by the fireworks, minimizing the intensity of the overall noise. In this way, this result must be analyzed with circumspection.

Concerning the analysis of tonal noise, it was verified that in the sample, $55 \%$ of the results presented a difference between two adjacent frequency bands greater than $5 \%$, characterizing tonal noise, and therefore, creating a greater disturbance to the surrounding community.

In the case of frequency spectrum analysis, it was found that the noise produced by fireworks, both in pyromusical and nonpyromusical events, has low-frequency characteristics. The only event that presented the highest intensity of noise at the medium frequency $(500 \mathrm{~Hz})$ was the one for children, which also presented tonal characteristics.

It is well known that low-frequency noise is the least aggressive but the most difficult to control because it diffracts, overcomes barriers and starts as a new source. However, in the evaluation of the risk of exposure to noise intensity it is a very important parameter, and in the specific case of events for children, peak values above $140 \mathrm{~dB}(\mathrm{C})$ were recorded, which characterizes a noise with an intensity well above that recommended by the (WHO) for children, in the case of $120 \mathrm{~dB}(\mathrm{C})$. Comparing with the European Union standards (120 dB (imp, A), the $\mathrm{L}_{\mathrm{Amax}}$ was $128 \mathrm{~dB}$ (imp, A) and therefore not compliant. The $\mathrm{L}_{\text {Aeq }}$ was $109.5 \mathrm{~dB}(\mathrm{~A})$, which is still very intense for children's ears, considering that the exposure time of this event was $29 \mathrm{~min}$. For $50 \%$ of this time, the noise was $91.5 \mathrm{~dB}(\mathrm{~A})$. It is common in this event that children cry out with screams and protect their ears when the puppets burst into flames when pyrophoric material is inserted. Since children are considered by WHO as part of the vulnerable group for exposure to noise, children's events require specific care regarding health and hearing.

It is important to note that these values were obtained at distances greater than the minimum permitted, which is $15 \mathrm{~m}$. This points to a revision of this value or the adoption of other measures such as: a greater distance from noise sources, reduction of the time of the explosion of the fireworks, use of individual protection, modification in the production process, producing fireworks that emit less intense noise and a modification of the project so it promotes the use of less noisy fireworks.

During the data collection, babies, children, young people and additionally many pregnant women, and elderly people were observed. All of which are considered to be vulnerable groups regarding noise exposure by WHO. In the recently published guidelines by the World Health Organization, for the burden of disease from environmental noise, it was concluded that future epidemiological noise research will need to focus on vulnerable groups such as children, elderly people, and lower socioeconomic groups [41]. This demonstrates the need to implement an environmental education program aimed at educating the population to the risks of exposure to noise at the evaluated events. It was also observed that many people, in the final moments of the presentation, when the noise levels are more intense, cover their ears with the hands due to the pain caused by the noise produced by the fireworks. Such a situation is impossible for babies and many kids. It was not uncommon to find children cuddling adults and crying during presentations, even during presentations intended for this audience, such as the trapped type fireworks (Festival and pilgrimages the city of Matosinhos), made with puppets, but producing a $\mathrm{L}_{\mathrm{Amax}}$ of $129.9 \mathrm{~dB}$ (A, imp) and with peak values greater than $140 \mathrm{~dB}(\mathrm{C})$. One of the authors used four types of different ear protectors during the events consisting of two inserts (earplugs), and two earmuff types, both approved by the European Community. The $3 \mathrm{M}$ earmuffs type, with an SNR of $27 \mathrm{~dB}$, prevented the author from feeling pain in the ears, the same occurred with the other, but did not present SNR values. The earplugs did not protect the author from ear pain. This was verified at the party of Guimarães, $L_{A \max }$ of 127.1 dB (A, imp) and peak level $>140 \mathrm{~dB}(\mathrm{C})$ and Vila Real, $\mathrm{L}_{\mathrm{Amax}}$ of $123.7 \mathrm{~dB}(\mathrm{~A}, \mathrm{imp})$ and peak level $>140 \mathrm{~dB}(\mathrm{C})$. Future studies should be carried out in order to verify the effectiveness of the use of such hearing protection at events with fireworks.

\section{Conclusions}

The noise levels evaluated show that the entire population of Northern Portugal, which participates in events like those evaluated, is exposed, on average, to values above the standards adopted by the Portuguese Police Authority as well as values set by the recent European Union Directive 2013 / 29. In the sample, it was verified that at $100 \%$ of the events, the exposure limits, set by WHO for children's fireworks, were exceeded and that the exposure value for adults was exceeded by $78 \%$. The analysis of the noise spectrum showed that most of the noise has low-frequency characteristics and that in 55\% of cases it has a tonal characteristic, which increases the annoyance level for the surrounding population. These results indicate that the exposed population may suffer from irreversible hearing damage, which constitutes a threat to the sustainability of the events. The results of the cumulative distribution of the noise produced by the firework display may generate the feeling of false safety in relation to the environmental noise agent thus indicating the need for better noise management by the organizers and a revision of the recent European Directive especially when addressing exposure limits for children. They further demonstrate that having a definite exposure limit is necessary, but not sufficient in avoiding hazardous exposures. As can be seen, babies, children, young people, and young adults in full productive phase from an occupational point of view, are exposed to noise comparable and even superior to heavy war weapons thus constituting a serious public health problem. All of which has direct effects on their quality of life and increased health costs and possibly a reduction in future employability.

It is necessary to establish noise management programs in these types of events, such as, among others: the right to information for the exposed persons, the reduction of the noise intensity, the use of silent fireworks, the reduction of exposure time, a better indication as to whether the presence of children should be allowed at such events, the use of hearing protection, a noise map of the event and the creation of a certification system for noisy events. As a suggestion for future research, we put forward investigating the effects of firework noise on the surrounding population, particularly the effects on people more sensitive to noise, such as babies, children, young, people with AD, PTSD, and Down's Syndrome.

\section{CRediT authorship contribution statement}

Robson Silva Passos: Conceptualization, Methodology, Investigation. Cecília Alexandra Abreu Coelho da Rocha: Supervision, Project administration. António Pedro Oliveira de Carvalho: Supervision, Project administration. Luiz Bueno da Silva: Statistical Review. Ricardo Luís Alves da Silva: Formal analysis. 


\section{Declaration of Competing Interest}

The authors declare that they have no known competing financial interests or personal relationships that could have appeared to influence the work reported in this paper.

\section{Acknowledgements}

We would like to thank the Federal Institute of Education, Science and Technology of Pernambuco, City Councils, Party Committees, Churches, Police, and the MESHO Laboratory for supporting this investigation.

\section{References}

[1] Mangili G, Pittaluga I, Schenone C. Analisi e Controllo Del Rumore Ambientale nell'area Del Centro Storico di Genova", 5a Giornata di Studio sull'Acustica Ambientale - 2012, Arenzano.

[2] EEA. European Environment Agency, Report Noise in Europe 2014, No 10/2014.

[3] Ottoza E, Rizzib L, Nastasi F. Recreational noise: impact and costs for annoyed residents in Milan and Turin. Appl Acoust 2018;133:173-81.

[4] Filipe CP. Encyclopedia of the popular and religious festivals of Portugal Catalogue of Portuguese festivals, fairs, and pilgrimages. 1st ed. Lulu.com 2008; p.03-17.

[5] Maassen M, Babisch W, Bachmann KD, Ising H, Lehnert G, Plath P, et al. Ear damage caused by leisure noise. Noise Health 2001;4:1-16.

[6] Smoorenburg GF. Risk of noise-induced hearing loss following exposure to Chinese firecrackers. Int J Audiol 1993;32:333-43.

[7] Mrena R, Savolainen S, Pirvola U, Ylikoski J. Characteristics of acute acoustical trauma in the Finnish Defense Forces. Int J Audiol 2004:43(3):177-81.

[8] Młynski R, Kozłowski E, Usowski J, Jurkiewicz D. Evaluation of exposure to impulse noise at personnel occupied areas during military field exercises. Arch Acoustics 2018;43(2):197-205.

[9] Basner M, Babisch W, Davis A, Brink M, Clark C, Janssen S, et al. Auditory and non-auditory effects of noise on health. Lancet 2014;383:1325-32.

[10] Flamme GA, Liebe K, Wong A. Estimates of the auditory risk from outdoor impulse noise I: firecrackers. Noise Health 2009:11:223-30.

[11] Cornacchia, L, Paolo L. Canalolithiasis due to a firework explosion: A case report.Audiological Medicine 2006; 4:82-4

[12] Maglieri, DJ, Hebert RH. Noise from aerial bursts of fireworks.1973. The Journal of the acoustical Society of America; 54:1224.

[13] Lou ZC, Lou ZH, Zhang QP. Traumatic tympanic membrane perforations: a study of etiology and factors affecting the outcome. American Journal of Otolaryngology 2012; 33:549-55

[14] Yamazaki K, Ishijima K, Sato H.A. Clinical study of traumatic tympanic membrane perforation. Nihon Jibiinkoka Gakkai Kaiho, 2010; 113: 679-86.

[15] Plontke SK, Dietz K, Pfeffer C, Zenner HP. The incidence of acoustic trauma due to New Year's firecrackers. Eur Arch Otorhinolaryngol 2002;259:247-52.

[16] Segal S, Eviatar E, Lapinsky J, Shlamkovitch N, Kessler A. Inner ear damage in children due to noise exposure from toy cap pistols and firecrackers: a retrospective review of 53 cases. Noise Health 2003:5:13-8.

[17] Mleczko K. The impact of fireworks noise on the acoustic climate in urban areas. Arch Acoustics 2018;43(4):697-705.

[18] WHO, Guidelines for community noise. Geneva. (1999) Available from: http:// www.who.int/docstore/peh/noise/guidelines2.html Access in 06/06/2020.

[19] The Fireworks Regulations 2004, in 2004 No. 1836. The UK by The Stationery Office Limited: London. Available from: http://www.legislation.gov.uk/uksi/ 2004/1836/made Access in 06/06/2020.

[20] Babu V, Azhagurajan A. Interpretation of safe parameters of chemical compositions and noise level of the fireworks crackers. Injury Prevention 2010;16:A58

[21] Tandon R, Agrawal K, Narayan RP, Tiwari VK, Prakash V, Kumar S, et al. Firecracker injuries during Diwali festival: the epidemiology and impact of legislation in Delhi. Indian J Plastic Surg 2012;45:97-101.
[22] Public Security Police of Portugal. Instructions on the use of pyrotechnic articles 28p Available from http://www.apipe.org/docs/INSTRUCAO\%20PSP\% 20FOGOS\%20ARTIFICO\%20aprovada.pdf Access in 06/06/2018.

[23] Commission of the European Communities (ECC Directive 2007/23 / EU of the European Parliament and of the Council on the harmonization of the laws of the Member States relating to the making available on the market of pyrotechnic articles (recast) L 15420072007.

[24] Commission of the European Communities (ECC 2013), Directive 2013/29 / EU of the European Parliament and of the Council on the harmonization of the laws of the Member States relating to the making available on the market of pyrotechnic articles (recast). L 178.2013.

[25] Jafari Z, Kolb BE, Mohajerani MH. Effect of acute stress on auditory processing: a systematic review of human studies. Rev Nurosci 2017;28:1-13.

[26] Jafari Z, Kolb BE, Mohajerani MH. Chronic traffic noise stress accelerates brain impairment and cognitive decline in mice. Exp Neurol 2018;308:1-12.

[27] Shannon G, McKenna MF, Angeloni LM, Crooks KR, Fristrup KM, Brown E, et al. A synthesis of two decades of research documenting the effects of noise on wildlife. Biol Rev Camb Philos Soc 2016;91:982-1005.

[28] Jafari Z, Bryan E, Kolb BE, Mohajerania MH. Noise exposure accelerates the risk of cognitive impairment and Alzheimer's disease: adulthood, gestational, and prenatal mechanistic evidence from animal studies. Neurosci Biobehav Rev 2019. https://doi.org/10.1016/i.neubiorev.2019.04.001.

[29] Sakhvidi MJZ, Fariba Zare Sakhvidi FZ, Mehrparvar AH, Foraster M., Dadvand P.,2018. Association between noise exposure and diabetes: A systematic review and meta-analysis. Environmental Research 166- 647-657. DOI:10.1016/j.envres.2018.05.011.

[30] Öhrström E, Skånberg A, Svensson H, Gidlöf-Gunnarsson A. Effects of road traffic noise and the benefit of access to quietness. J Sound Vib 2006;295 (1):40-59.

[31] Wallas A.E., Eriksson C, Bonamy A, Gruzieva O,Kull I, Ögren M, Pyko A, Sjöström M,Pershagen G. 2019. Traffic noise and other determinants of blood pressure in adolescence.222. 824-830. DOI:10.1016/j.ijheh.2019.04.012.

[32] DELTA Acoustics \& Electronics. The "Genlyd" Noise Annoyance Model: DoseResponse Relationships Modelled by Logistic Functions. (2007). (1102) Retrieved from Made by Delta website: https://dk.madebydelta.com/ publikation/the-genlyd-noise-annoyance-model/ Access in 06/06/2020.

[33] Kukulski B, Wszołek T, Killin LO, Starr JM, Shiue IJ, Russ TC. Environmental risk factors for dementia: a systematic review. BMC Geriatric 2016;16:175.

[34] Gottesman RF, Albert MS, Alonso A, et al. Associations between midlife vascular risk factors and 25-year incident dementia in the Atherosclerosis Risk in Communities (ARIC) cohort. JAMA Neurol 2017;74:1246-54.

[35] Oudin A, 2020. Short review: Air pollution, noise, and lack of greenness as risk factors for Alzheimer's disease- epidemiologic and experimental evidence. Neurochemistry International.

[36] OECD Health at a Glance 2017: OECD Indicators OECD Publishing, Paris. 2017 10.1787/health_glance-2017-en

[37] Santana I, at. al. The Epidemiology of Dementia and Alzheimer's Disease in Portugal: Estimations of Prevalence and Treatment-Costs. Acta Med Port 2015 Mar-Apr;28(2):182-188.

[38] Harvard Medical School. Sound and Fury: Understanding Post-Traumatic Stress Disorder (2014). Paper presented at The Longwood Seminars, Harvard Medical School. https://hms.harvard.edu/sites/default/files/assets/Sites/ Longwood_Seminars/April\%2010\%20PT SD.pdf, Access in 07/06/2020.

[39] Albuquerque, A., Soares, C., Jesus, P., \& Alves, C. (2003). The Epidemiology of PTSD in the Adult Population in Portugal, 309-320. Retrieved from Acta Médica Portuguesa website: https://actamedicaportuguesa.com/revista/index.php/ amp/article/download/1209/861. Access in 06/06/2020.

[40] (a) Osório, C., Greenberg, N., Jones, N., Goodwin, L., et al.,2013. Combat exposure and posttraumatic stress disorder among Portuguese special operation forces deployed in Afghanistan. Military Psychology, 25(1), 70-81. (b) Paddan GS. Occupational noise exposure on a Royal Navy warship during weapon fire. Noise Health 2016; 18:266-73.

[41] Fritschi L, Brown AL, Kim R, Schwela D, Kephalopoulos S, editors. Burden of Disease from Environmental Noise. Quantification of Healthy Life Years Lost in Europe. Copenhagen: WHO Regional Office for Europe; 2011.134. DOI:10.1016/j.neuint.2019.104646. 